\title{
Las elecciones olvidadas: 1948 a 1949*
}

\section{Carolina Mora Chinchilla** \\ DOI 10.35242/RDE_2019_27_12}

\section{Nota del Consejo Editorial}

Recepción: 10 de octubre de 2018.

Revisión, corrección y aprobación: 7 de noviembre de 2018.

Resumen: En Costa Rica, con el fin de la Guerra Civil de 1948 y el establecimiento de la Junta de Gobierno presidida por José Figueres Ferrer en 1948, se van a suceder una serie de hechos electorales y legales que es importante recordar, porque permiten legitimar el gobierno de Otilio Ulate Blanco (1949-1953). Las elecciones que se efectuaron entre diciembre de 1948 y octubre de 1949, organizadas por el Tribunal Supremo de Elecciones (TSE), son el tema de este trabajo, debido a que han sido "olvidadas", no ignoradas, en la historia nacional. La particularidad de estos procesos convocados con nuevas y viejas reglas del juego político-electoral nos lleva a concluir que la fortaleza con la que se dotó al TSE, en esos primeros momentos, posibilitó en gran medida el retorno de la política a derecho y la futura paz electoral del país hasta la fecha.

Palabras clave: Historia electoral / Historia política / Legitimidad política / Estabilidad política / Fortalecimiento de la democracia / Convocatoria a elecciones / Administración electoral / Tribunal Supremo de Elecciones.

Abstract: In costa Rica, with the end of the Civil War of 1948 and the establishment of the Government Board presided by José Figueres Ferrer in 1948, a series of electoral and legal events took place and it is important to remember them since they legitimize the government of Otilio Ulate Blanco (1949-1953). This work addresses the elections that took place between December 1948 and October 1949, organized by the Supreme Electoral Tribunal (TSE). These elections have been "forgotten", not ignored in national history. The distinctive feature of theses processes, with old and new rules of the political and electoral game, leads us to conclude that the power given to the TSE in those first moments made it possible for the rule of law to return to politics and to the future electoral peace of the country to this date.

Key Words: Electoral history / Political history / Political legitimacy / Political stability / Strengthening of democracy / Call for elections / Electoral administration / Supreme Electoral Tribunal.

\footnotetext{
* Un especial agradecimiento a Rocío Montero Solano, jefa del Centro de Documentación del Instituto de Formación y Estudios en Democracia del TSE por su desinteresada ayuda en la búsqueda de muchos de los documentos aquí citados.

${ }^{* *}$ Costarricense, historiadora, correo cmora@tigomail.cr. Bachiller y máster en Historia de la Universidad de Costa Rica. En la actualidad es directora de la Revista Estudios de la Sección de Historia de la Cultura de la Escuela de Estudios Generales de la Universidad de Costa Rica. Profesora y coordinadora de dicha Sección. Autora de los libros Globalización y democracia: América latina en busca de una mejor representatividad política (2003), Ventanas al Pasado (1914), Los derechos humanos. Multiculturalidad y ciudadanía en un mundo globalizado (2016) y de diversos artículos en revistas especializadas.
} 


\section{DERECHO ELECTORAL}

\section{LA MEMORIA NO EXISTE, SE CONSTRUYE}

El pasado 20 de abril se incluyó la "Colección del cómputo de votos de las elecciones 1949-2016" en el Programa de la Memoria del Mundo, un registro mundial de documentos que preserva la UNESCO. En la noche, en una conversación casual, mi esposo y presidente del Tribunal Supremo de Elecciones, al mencionar este acto, hizo referencia a las elecciones que se efectuaron para elegir diputados a la Constituyente (1948) y en especial a una elección de diputados que casi nunca se menciona, la efectuada el 2 de octubre de 1949. Sorprendida de mi poco conocimiento sobre el tema, me sugirió hacer el trabajo que aquí presento. El título lo propuso él mismo, "las elecciones olvidadas", ya que no son elecciones a las que se haga referencia a menudo, pero quedaron preservadas en estos valiosos documentos que hoy, junto con otros, ayudarán a que en el futuro se puedan construir estas memorias.

Se puede generalizar que, en la historia nacional, a menudo se diluyen en las aguas del olvido hechos que en su momento fueron de gran relevancia. Sobre la Guerra Civil de 1948, continuamente salen a la luz nuevas investigaciones, revisiones de fuentes que vuelcan por completo la "historia oficial", datos analizados desde muy diversas perspectivas, pero se han ido quedando en el limbo una serie de actos legislativos y electorales posteriores.

La memoria de lo acontecido luego de la lucha civil en pocas ocasiones recuerda que cuando el Tribunal Nacional Electoral (creado en 1946) le dio el triunfo al Partido Unión Nacional en la elección presidencial, el 11 de febrero de 1948, y declaró electo a Otilio Ulate Blanco como ganador de las conflictivas elecciones, las elecciones de diputados y de autoridades municipales no se cuestionaron.

Dicho Tribunal, como es sabido, estaba constituido por un representante de cada poder: el Poder Ejecutivo había nombrado a Gerardo Guzmán, el Poder Judicial a José María Vargas, que dictaminaron a favor de Otilio Ulate, y Max Koberg, del Poder Legislativo, quien salva su voto, aduciendo la falta de documentos que fundamenten la elección. Es por esto que casi todos los diputados del partido Republicano, en unión con los seis diputados comunistas, votaron a favor de anular las elecciones presidenciales el 1 de marzo de 1948.

La declaratoria de elección, por parte del Tribunal Nacional Electoral, era provisional y se enviaba al Congreso Nacional para que se ratificara. El 


\section{DERECHO ELECTORAL}

Congreso en esta ocasión optó por anular la elección presidencial, alegando manipulación del padrón electoral y de los datos, muchos de ellos enviados por telegrama.

Investigadores como Iván Molina y David Díaz, costarricenses y Fabrice Lehoucq, estadounidense, entre otros, han dado un giro total a la historia oficial de las elecciones presidenciales de 1948 y los hechos que le sucedieron. Han sido conocidos y discutidos con amplitud y aún hoy siguen surgiendo nuevos datos, otras perspectivas y nuevas interpretaciones.

Para el caso concreto de lo electoral, Molina señala la gran diferencia entre los votos obtenidos para presidente y para diputados. Dado que para presidente gana Ulate del Unión Nacional y para diputados ganan el Republicano y Vanguardia Popular (según dictamen del Tribunal Nacional Electoral), "¿puede aceptarse que un número tan elevado de votantes (10.000 como mínimo) sufragara diferencialmente en un contexto de tanta polarización política e ideológica como el que existía en 1948?" (Molina, 2001, p. 51). De acuerdo a los relatos de muchos participantes en estas elecciones que han dejado sus testimonios en diversas fuentes, esto era casi imposible, precisamente por la violenta campaña electoral que precedió a las elecciones y que, como bien explican los estudiosos del tema, dividió al país.

Molina (2001, p. 59) remarca el número de votos logrados por el Republicano y el Vanguardia Popular (Bloque de la Victoria): en total obtienen 44438 para presidente y para diputados 53337 , mientras que el Unión Nacional para presidente obtuvo 54931 y para diputados 41211.

¿La oposición ulatista aceptaría un gane presidencial con el Congreso en contra? De los 27 diputados que votaron por la anulación de las elecciones el 1 de marzo de 1948, 26 hubieran continuado por lo menos hasta 1950. Los diputados del Vanguardia Popular, Luis Carballo, Manuel Mora, Alfredo Picado, José Fernández, Carlos Luis Fallas y Jaime Cerdas fueron parte de este grupo. En todo caso, la elección presidencial se anuló, pero la de diputados y de gobiernos locales no se discutió. Las inconsistencias que se señalaron respecto de las presidenciales y el voto salvado de Max Koberg, en el que aduce falta de documentación, hicieron que un Congreso dominado por el Partido Republicano y con el apoyo de varios diputados del Vanguardia Popular la anularan. Tanto Calderón como Ulate habían declarado públicamente que se respetaría el fallo del Tribunal Nacional Electoral, lo cual no sucedió como se sabe. 


\section{DERECHO EIECTORAL}

Luego de más de un mes de lucha y tras la firma de varios pactos o acuerdos, se determinó que Otilio Ulate asumiría la presidencia de la República el 8 de noviembre de 1949, tras un periodo de año y medio de gobierno de la Junta Fundadora de la Segunda República, presidida por José Figueres $\mathrm{F}$.

Tumbado el gobierno de Teodoro Picado, la Junta Fundadora de la Segunda República derogó la Constitución de 1871.

Exceptuando sus capítulos referentes a las garantías individuales, nacionales y sociales, cuya vigencia se restablécese provisionalmente. En el artículo $2^{\circ}$ de dicho decreto se especificó que se mantenían también provisionalmente la vigencia de todos los Códigos y Leyes de la República, con la salvedad de la Ley Orgánica del Poder Judicial y en su punto $3^{\circ}$ la Junta se dejó la facultad de decretar reformas a los textos constitucionales, códigos y leyes que consideren pertinentes (Actas, Asamblea Nacional Constituyente, tomo I, 1951, 10) (Obregón, 2008, p. 342).

Otra de las disposiciones de la Junta (2 de junio de 1948) fue la modificación de la ley electoral para que el nombramiento del Tribunal Electoral se hiciera por decreto, así como el director del Registro Civil. Como magistrados se nombró a: Carlos Orozco Castro, presidente, Juan Rafael Calzada Carboni y Gonzalo Echeverría Flores, y como suplentes los señores Antonio Vargas Quesada, Mariano Echeverría Morales y Otón Acosta Jiménez (Decreto-ley N. ${ }^{\circ} 47$ de 4 de junio de 1949).

Además, el 14 de setiembre de 1948 cambió el nombre de Tribunal Nacional Electoral por Tribunal Supremo de Elecciones (Decreto N. ${ }^{\circ} 171$ de la Junta Fundadora de la Segunda República, en Obregón, 2008, p. 343).

Era necesario reconfigurar adecuadamente la institucionalidad electoral, para poder elegir a los diputados constituyentes y, luego, a los del nuevo Poder Legislativo.

Una vez instalada esa Constituyente y a solicitud de la Junta, el 16 de enero de 1949 ratifica a Otilio Ulate como presidente vencedor del proceso electoral del 8 de febrero de 1948: 


\section{DERECHO ELECTORAL}

\section{LA ASAMBLEA NACIONAL CONSTITUYENTE DE LA REPUBLICA DE COSTA RICA}

Considerando:

10.- Que en las elecciones verificadas el día 8 de febrero de 1948 resultó electo Presidente Constitucional de la República don Otilio Ulate Blanco, según aparece del fallo pronunciado por el Tribunal Nacional Electoral a las 10 horas y 30 minutos del 28 de febrero de 1948. 20.- Que aun cuando se pretendió anular dicha elección por una mayoría de veintisiete diputados que, olvidando el compromiso de honor que habían contraído, dictó el vergonzoso acuerdo de $1^{\circ}$ de marzo de ese mismo año, es lo cierto que en la conciencia nacional se mantuvo incólume la convicción de que el resultado de la elección había favorecido al señor Ulate Blanco. 30.- Que el resultado de las elecciones del 8 de diciembre último significa una ratificación plena al señor Ulate de la confianza y de la voluntad nacionales. 40.- Que desaparecido el régimen nefasto que propició la burla del sufragio popular, es imperativo reconocer la absoluta legalidad de la elección del señor Ulate, y declarar la inexistencia e ineficacia del mencionado acuerdo de $1^{0}$ de marzo de 1948. 50.- Que el reconocimiento de la legalidad de esa elección, y la ratificación de la misma, es función que corresponde a la Asamblea Nacional Constituyente, según el Decreto-Ley de convocatoria, número 151 de 3 de setiembre de 1948.

\section{DECRETA:}

Artículo $1^{\circ}$.- Se declara inexistente $y$, en consecuencia, sin ningún valor ni efecto, la nulidad de la elección presidencial del 8 de febrero de 1948, decretada por el Congreso Constitucional el 10 de marzo del propio año; y con vista del resultado de esa votación y acatando el fallo pronunciado por el Tribunal Nacional Electoral a las 10 horas y 30 minutos del 28 del mismo mes de febrero, declárase constitucionalmente electo a don Otilio Ulate Blanco para ejercer la Presidencia de la República por un período de cuatro años.

Artículo 20.- Como el período presidencial del señor Ulate fue modificado, en cuanto a su fecha de iniciación, por el Pacto de Honor suscrito el $1^{\circ}$ de mayo de 1948 entre don José Figueres 


\section{DERECHO ELECTORAL}

y don Otilio Ulate, dicho período comenzará el día en que el señor Ulate tome posesión de su alto cargo. (Asamblea Nacional Constituyente, Art. 6 del Acta n. ${ }^{\circ} 2,1949$ ).

\section{El Tribunal Supremo de Elecciones y la elección de los diputados CONSTITUYENTES (8 DE DICIEMBRE DE 1948)}

Las medidas tomadas por la Junta Fundadora de la Segunda República obligan a establecer un calendario electoral interesante, que empezaría el 3 de setiembre de 1948, con la convocatoria a una elección de diputados constituyentes. En ese momento, el órgano encargado de tal tarea aún se Ilamaba Tribunal Nacional Electoral. La elección se llevó a cabo el 8 de diciembre del mismo año, siendo esta la primera vez en la que participa como tal el Tribunal Supremo de Elecciones, denominado así por el decreto N. ${ }^{\circ} 171$ de la Junta, del 14 de setiembre de 1948.

En el acta decimoséptima del 3 de enero de 1949, en la que se anotan los resultados de dicha elección, el TSE recuerda en primer lugar que "por Decreto 151 de la Junta Fundadora de la Segunda República se convocó a los ciudadanos a elecciones para Diputados a la Asamblea Nacional Constituyente"; y, en segundo lugar, que "la inscripción de los Partidos se conformó primero, con el decreto n. ${ }^{\circ} 170$ del 3 de setiembre de este año, concediendo facilidades a las agrupaciones políticas que participaran en las elecciones penúltimas de febrero..." [El resaltado es propio].

El 8 de diciembre se acudió a las urnas para elegir a los diputados que elaborarían la nueva Carta Constitucional. Se inscribieron 7 partidos políticos: Unión Nacional, Constitucional, Social Demócrata, Confraternidad Nacional, Acción Cívica, Movimiento Republicano Popular y Liberal. Es importante aquí anotar que faltan dos partidos de las "elecciones penúltimas de febrero", el Republicano y el Vanguardia Popular. Así que, desde un inicio, fueron excluidos de la toma de decisiones a nivel constitucional.

Los resultados que se observan son los siguientes: el partido Unión Nacional obtuvo 34 diputados, el partido Constitucional 6, el Social Demócrata 4 y el Confraternidad Nacional solo uno (según lo acredita el TSE). Aún no estaba vigente la Constitución de 1949, por lo cual de nuevo fue una elección en la que votaron solo los hombres mayores de 21 años. 


\section{DERECHO ELECTORAL}

El ambiente de posguerra civil, el exilio de muchos calderonistas y comunistas, así como la facilitación consecuente que tuvo el partido Unión Nacional, cuyo presidente electo estaba esperando que pasaran 18 meses para asumir el poder (de acuerdo con el Pacto que había firmado con José Figueres, líder vencedor de la lucha civil), hicieron posible una votación rotunda a favor del Unión Nacional.

Las decisiones de la Asamblea Nacional Constituyente no son materia de este trabajo; sin embargo, se debe recordar que utilizó como base de discusión la Constitución de 1871 y, en materia electoral, aprobó el voto femenino y proscribió al partido comunista. Además, fortaleció el Tribunal Supremo de Elecciones y se dispuso que el Registro Civil pasaría a ser dependencia exclusiva de este órgano, al que se le dio rango de órgano constitucional. Desde ese momento el Registro Civil será el responsable de "llevar un Registro Central del Estado Civil, y formar las listas de electores" (Obregón, 2008, p. 360).

Como adelantaba, una de las primeras disposiciones de la Asamblea Nacional Constituyente fue legitimar, el 16 de enero de 1949, la elección de Ulate.

Según explica David Díaz (2015), una marcha para apoyar a Ulate convocada por Emma Gamboa en mayo de 1948 había "obligado" a Figueres a respetar el acuerdo con Ulate, quien no estuvo conforme con que la Junta de Gobierno asumiera el poder por 18 meses. De acuerdo al pacto UlateFigueres, lo primero que se estipula es que: "La Junta Revolucionaria gobernará al país sin Congreso durante un período de dieciocho meses a partir del ocho de mayo en curso. Expirando dicho término podrá solicitar a la Asamblea Constituyente una prórroga por seis meses si lo considera necesario para sus labores" (Castro, 2007, p. 56).

A Ulate se le ofreció la presidencia de la Junta, aunque la rechazó. No era militar. Su posición fue clara. Así que, por acuerdo político, Ulate sería presidente, postergando su ascenso y la Junta, al tomar el poder de facto, gobernaría sin Congreso ni Constitución.

\section{UNA NUEVA ELECCIÓN: VICEPRESIDENTES, DIPUTADOS Y REGIDORES (4 DE OCTUBRE DE 1949)}

Al asumir la Junta Fundadora de la Segunda República y con la derogatoria de la Constitución de 1871, desapareció por las razones antes mencionadas, 


\section{DERECHO EIECTORAL}

entre otros, el Congreso Constitucional de la República de Costa Rica. En el Pacto Ulate-Figueres del 1 de mayo de 1948 esto quedó así estipulado:

La Junta Revolucionaria gobernará al país sin Congreso durante un período de dieciocho meses a partir del ocho de mayo en curso. Expirando dicho término podrá solicitar a la Asamblea Constituyente una prórroga por seis meses si lo considera necesario para sus labores. (1948, párr. 1).

Según lo comentado, la anulación de las elecciones presidenciales del 1 de marzo de 1948 no cuestionó la elección de estos representantes efectuada en febrero de 1948. La declaratoria provisional de la elección de los diputados fue dada a conocer en el Congreso el 9 de abril de 1948 y publicada en la Gaceta del 18 de abril. En ella se dispone que, además de ser conocida por el Congreso, deberá comunicarse al Poder Ejecutivo y a los diputados electos.

El hecho es que, al día siguiente de esta publicación en La Gaceta, "se firmó en la Embajada de México, en San José, el documento de rendición de las fuerzas gubernamentales que puso fin a la guerra civil, tras conversaciones entre los rebeldes, el presidente Picado y los miembros del Cuerpo Diplomático acreditado en el país" (Castro, 2007, p. 11).

Como ha sido explicado ampliamente por la literatura sobre la época, Picado es obligado a renunciar, a exiliarse y, en su lugar, Santos León Herrera asumió interinamente la presidencia hasta el 8 de mayo de ese año, día en que asume la Junta Fundadora de la Segunda República.

Cayó el gobierno de Teodoro Picado que había sido electo democráticamente $\mathrm{y}$, como gobierno de facto, la Junta asume los poderes Legislativo y Ejecutivo del Estado (Costa Rica. Junta Administradora de la Segunda República, Decreto 1 art. 3, 1948). Con estos hechos se desconoce la elección de diputados que integrarían el Congreso Constitucional, a partir del 1 de mayo de $1948^{1}$, cuya mayoría era contraria a Ulate. Igual sucedió con la elección de autoridades municipales.

\footnotetext{
1 Según la Constitución de 1871, art.76, "Los diputados durarán en sus destinos cuatro años, debiendo ser renovados cada dos años por mitades, y pudiendo ser reelectos indefinidamente" [resaltado propio]. En la elección de diputados de 1948, de los 27 diputados que votaron por la anulación de la elección de Ulate, salvo Álvaro Cubillo Aguilar del Partido Republicano, continuaban en el Congreso al menos hasta 1950.
} 


\section{DERECHO ELECTORAL}

Esto, aunado al reconocimiento de Otilio Ulate como legítimo presidente, representa el problema de no contarse con un Poder Legislativo integrado. Ulate asumiría el 8 de noviembre de 1949, con una Constitución nueva, puesta en vigencia el día anterior. Por ello fue necesaria una nueva elección. El Tribunal Supremo de Elecciones recién "estrenaba" un nuevo texto que le había enviado la Asamblea Nacional Constituyente:

No 9

LA ASAMBLEA NACIONAL CONSTITUYENTE,

\section{DECRETA:}

Enviar al Tribunal Supremo de Elecciones el texto revisado de los capítulos correspondientes al Sufragio - Tribunal Supremo de Elecciones - Poder Legislativo - Atribuciones de la Asamblea Legislativa - Formación de Leyes - Poder Ejecutivo y Régimen Municipal, y ordenar a ese Alto Cuerpo que proceda inmediatamente a lo de su cargo (artículos 75 y siguientes), de conformidad con lo resuelto por la Asamblea Nacional Constituyente en relación con los capítulos precitados, los cuales quedan definitivamente aprobados en cuanto al fondo. (Costa Rica. Colección de Leyes y Decretos, 1949, 21)

De esta manera, el TSE fue dotado de una normativa renovada por la Asamblea Constituyente. El 12 de julio de 1949, el órgano electoral dispone lo siguiente:

1- De acuerdo con el Decreto $N^{\circ} 9$ de la Asamblea Nacional Constituyente y los capítulos relativos al Tribunal Supremo de Elecciones, Poder Legislativo, Poder Ejecutivo y Régimen Municipal, convócase a los ciudadanos a elecciones para Vicepresidentes de la República, Diputados a la Asamblea Legislativa, Regidores y Síndicos Municipales.

2- El número de Vicepresidentes es de dos.

Carlos Orozco, Gonzalo Echeverría, Juan Rafael Calzada. (Costa Rica. Colección de Leyes y Decretos, 1949, p. 45) [El resaltado es propio].

Esta fue una elección diferente. Los candidatos a vicepresidentes fueron propuestos únicamente por el Partido Unión Nacional. Los candidatos a 


\section{DERECHO EIECTORAL}

diputados y regidores los postularon esta y otras organizaciones políticas como el Partido Demócrata Cortecista, el Social Demócrata y el Constitucional, según consta en la papeleta de diputados por San José de 1949, facilitada por el Centro de Documentación del TSE.

EI TSE convoca para el 2 de octubre a "elecciones anticipadas" para elegir diputados a la Asamblea Legislativa y regidores municipales. Anticipadas porque la prórroga de seis meses que le había otorgado la Asamblea Constituyente a la Junta fue rechazada por Figueres y hubo que convocar a elecciones para diputados y autoridades municipales, antes de finalizar el año. Esto fue esencial para que constitucionalmente el gobierno de Otilio Ulate estuviera en regla.

Los vicepresidentes fueron una figura nueva. En la Constitución de 1871 se utilizaba la denominación "designados a la Presidencia", escogidos por el Congreso Constitucional; al estar derogada, había que presentar una nueva fórmula, que a la larga resultó más democrática. Salvo en esta primera elección de vicepresidentes, ya que Alberto Oreamuno Flores y Alfredo Volio Mata, del Partido Unión Nacional, fueron los únicos candidatos, por obvias razones políticas.

Vladimir de la Cruz recientemente en un artículo en el diario La República dice:

Durante los procesos electorales desarrollados a partir de 1949, para elegir diputados del Congreso Constitucional, que acompañaría la Presidencia de Otilio Ulate, 1949-1953, no se permitió participar a los comunistas... la Junta Fundadora de la Segunda República ese 17 de julio de 1948 proscribió partidos políticos e impidió que ciudadanos pudieran organizarse electoralmente para votar por sus propias opciones. (18 de julio de 2018, párr. 10).

Habría que agregarle que tampoco el Republicano Nacional con este nombre, aunque muchos de sus partidarios se aglutinaron alrededor de las otras agrupaciones.

Algunos diputados constituyentes figuraron como candidatos en las elecciones de diputados, por ejemplo: Marcial Rodríguez Conejo (quien presidió inclusive la Asamblea Nacional Constituyente), Ramón Arroyo Blanco y Celso Gamboa Rodríguez. Otros, como Fernando Lara Bustamante, 


\section{DERECHO ELECTORAL}

Antonio Peña Chavarría y Numa Ruiz Solórzano, habían sido diputados en 1948.

Para el caso de las elecciones de regidores cabe resaltar que participaron, además, partidos de carácter cantonal exclusivamente, como el Unión Cartaginesa, el Independiente de Atenas, el Ulatista de Palmares, el Unión Independiente de Turrialba y el Unión Cantonal de Carrillo (TSE, Tomo I de Candidaturas, pp. 167-312).

Un dato interesante que se presenta en la convocatoria del 12 de julio de 1949 se observa en lo referente al nombramiento de los síndicos: "5- La Asamblea del cantón designará al mismo tiempo, los Síndicos propietarios y suplentes que correspondan al número de distritos del respectivo cantón" (Costa Rica. Colección del Leyes y Decretos, 1949, p. 47). Al parecer no fueron nombrados en esta elección.

\section{Conclusiones}

Lo hasta aquí explicado encierra distintas paradojas y contradicciones, antes y después de la guerra civil, que únicamente se pueden entender desde una perspectiva política.

En primer lugar, si el viejo congreso constitucional estimaba que no era posible establecer con claridad la voluntad popular expresada en las elecciones de 1948, debió anular también los comicios concurrentes de diputados.

En segundo lugar, si los alzados en armas actuaban en defensa de la pureza del sufragio, debieron no solo restituir a Ulate en su cargo presidencial, sino también reconocer el mandato parlamentario resultante de las urnas y, una vez estabilizado políticamente el país, restablecer la vigencia de la Constitución de 1871.

Esto no sucedió, sino que la Junta Fundadora de la Segunda República, en su condición de gobierno de facto, consolidó una ruptura del orden constitucional y convocó a un proceso constituyente.

Acá surge una tercera contradicción: la ortodoxia doctrinaria explica que, en estos casos, el mandato de todos los gobernantes automáticamente y sin excepción decae $y$, una vez promulgada la nueva Constitución, se procede a elegir a los nuevos, en armonía con la reconfiguración del Estado 


\section{DERECHO ELECTORAL}

dispuesta por el pueblo soberano. Tampoco aconteció de esta manera, porque la Constituyente terminó legitimando la presidencia de Ulate, nacida en los estertores del ancien régime.

La lógica política era, desde luego, otra. El partido del gobierno anterior al conflicto civil no quería desconocer una elección de diputados que le favorecía ampliamente. El figuerismo, luego de los hechos bélicos, no toleraba la pervivencia política de calderonistas y comunistas que, además, hubieran dominado el nuevo poder legislativo. Y, por último, para el ulatismo era inaceptable tener que someterse a una nueva elección.

El discurso histórico de los vencedores pasa por alto la elección de diputados de 1949. Se trata de un conveniente olvido, porque evita el cuestionamiento de los mitos y héroes oficiales que podría suscitarse al desenredar esta madeja de paradojas.

La historia de los vencidos por lo general se olvida y olvidar estas elecciones tuvo ese claro objetivo político. Sin embargo, un importante hecho, como el del pasado 20 de abril, permitió revisar parte de estos "documentos únicos que testimonian la esencia de una de las democracias más estables y longevas de Latinoamérica, así como de seguir garantizando su accesibilidad universal" (Luis Antonio Sobrado, discurso en la Biblioteca Nacional, acto de entrega oficial del Certificado de Registro de Memoria del Mundo).

Definitivamente han tenido que pasar muchos años y cientos de páginas escritas, en su mayoría por los vencedores, para poder "recordar" objetivamente lo sucedido tras la guerra civil. La historia oficial ha sido eficiente en olvidar muchos hechos, pero por suerte contamos con documentos esenciales que refrescan la memoria histórica. Preservar el patrimonio documental del cómputo de votos de las elecciones organizadas por el TSE, en la Memoria del Mundo, permite conocer y reconstruir parte importante de nuestra historia y muestra la responsabilidad de los encargados de proteger este acervo al ponerlo en las manos adecuadas.

Pasados los dieciocho meses de gobierno de la Junta, presidida por Figueres y con Ulate en la presidencia, los 45 diputados propietarios y los 15 suplentes en sus curules y los regidores y síndicos en sus puestos cantonales y distritales, parecía que la normalidad de la vida política costarricense se había recobrado. Todavía quedaba uno que otro sobresalto más, producto de todos los hechos del 48. 


\section{DERECHO ELECTORAL}

No se puede dejar de pensar en lo que se ganó y lo que se perdió con esta situación. Por ejemplo, de acuerdo a la nueva Constitución, se puso fin a lo que se ha llamado "carrera parlamentaria", para bien y para mal. Sin lugar a dudas, la experiencia acumulada de muchos buenos diputados hoy se extraña, ya que el voto en principio premiaría a los mejores representantes populares.

Por otra parte, se debe recordar que los magistrados que participaron durante los eventos electorales aquí narrados fueron propuestos por la Junta presidida por José Figueres Ferrer. Cumplieron a cabalidad con sus funciones y de muchas formas dieron esa necesaria legitimidad, seguridad y respeto a los eventos político-electorales que se vivieron. Esto se fortaleció aún más al adquirir el TSE rango de órgano constitucional en la carta de 1949.

Para terminar, solo queda mencionar una última elección, aunque esta es de otra índole: los primeros magistrados del Tribunal Supremo de Elecciones designados por la Corte Suprema de Justicia en mayo de 1951. En esta ocasión escogieron figuras que ya habían fungido como encargados del órgano electoral: Carlos Orozco Castro (presidente), Juan Rafael Calzada Carboni (secretario) y Gonzalo Echeverría Flores (vocal).

Evidentemente estos hechos forjaron una nueva autoridad electoral en Costa Rica y, con la experiencia adquirida en estas lides, el TSE tuvo un papel preponderante en la consecución de un nuevo modelo político, que pudo tener muchas falencias, pero que llevó al país por una senda democrática que muchos otros envidian hoy.

\section{REFERENCIAS BIBLIOGRÁFICAS}

Aguilar, O. (1970) Costa Rica y sus hechos políticos de 1948 Problemática de una década. San José, C.R.: Editorial Costa Rica.

Castro, O. (2007) Fin de la Segunda República. Figueres y la Constituyente del 49. San José, C.R.: EUNED.

Costa Rica (1949). Actas de la Asamblea Nacional Constituyente de versión digital revisada por Rodolfo Saborío Valverde Saborío y Coto Abogados. Recuperado de http://www.cesdepu.com/actas/anc49.htm 


\section{DERECHO EIECTORAL}

Costa Rica (1949). Colección de leyes y decretos. San José, C.R.: Imprenta Nacional.

Costa Rica. Junta Administradora de la Segunda República (1948). Decreto-ley n. ${ }^{\circ}$ del 8 de mayo. Recuperado de https://elespiritudel48.org/junta-fundadorade-la-segunda-republica/

Costa Rica. Tribunal Supremo de Elecciones (1948). Libro de actas de 1948-1949. San José, C.R.: Tribunal Supremo de Elecciones.

Costa Rica. Tribunal Supremo de Elecciones (1948). Registro de candidaturas, tomo I, pp. 167-312. San José, C.R.: Tribunal Supremo de Elecciones.

De la Cruz, V. (18 de julio 2018). El Decreto n. 105. Diario La República, Columna Pizarrón. Recuperado de https://www.larepublica.net/noticia/el-decreto-no105

Molina, I. (2001) Estadísticas Electorales de Costa Rica (1897-1948). Una contribución documental. Recuperado de: https://revistas.ucr.ac.cr/index.php/dialogos/article/viewFile/6323/6025.

Molina, I. (2001) Democracia y Elecciones en Costa Rica. Dos contribuciones polémicas. San José, Costa Rica: FLACSO.

Molina, I. (2005) Demoperfectocracia. Heredia, Costa Rica: EUNA.

Montero, R. y Zamora, K. (Enero-Junio, 2010). Hechos relevantes del Tribunal Supremo de Elecciones 1946-2009. Revista de Derecho Electoral, (9), 236-178. Recuperado de: http://www.tse.go.cr/revista/impresa/revista9.pdf

Obregón, R. (1966) El Poder Legislativo en Costa Rica. San José, Costa Rica: Universidad de Costa Rica.

Obregón, C. (2008) El proceso electoral y el Poder Ejecutivo en Costa Rica. San José, Costa Rica: Editorial de la UCR.

Pacto Ulate-Figueres (1948). Recuperado de https://elespiritudel48.org/pactoulate-figueres/

Sobrado, Luis Antonio (2018) Discurso en el Acto de entrega oficial del Certificado de Registro de Memoria del Mundo: Biblioteca Nacional de Costa Rica, 20 de abril de 2018.

Zeledón, M.T. (1946) Digesto Constitucional. San José, Costa Rica: Colegio de Abogados. 